\title{
Force Feed Effects on Process Stability in Turning
}

\author{
K. Rama Kotaiah ${ }^{a}$, J. Srinivas ${ }^{b}$ and M. Sekar ${ }^{c}$ \\ ${ }^{a}$ Dept. of Industrial and Production Engineering, K.L.College of Engineering, Vaddeswaram, Guntur (Dist), Andhra \\ Pradesh, India-522502, ${ }^{b}$ Dept. of Mechanical Engineering, Chaitanya College of Engineering, Kommadi, \\ Visakhapatnam, Andhra Pradesh, India and ' School of Mechanical Engineering, Kyungpook National University, \\ Daegu, South Korea.
}

\begin{abstract}
This paper presents analytical stabiltity analysis of turning using non-linear force-feed model in two dimensions. Most of the existing analytical models ignored the effect of static feed term on the regeneration phenomenon. In practice there is a marked effect of feed on stability due to force variation. The modified analytical equations for cutting insert using three dimensional too geometry are obtained by considering relative motion of tool with respect to a two dimensional elastic model of work-piece. The critical stability limits obtained as a function of feed are confirmed with time domain analysis. Experiments are conducted on a flexible work-piece at varying feed conditions. The measured cutting forces show a marked effect of feed on stability. A neural network models developed to obtain the critical depth of cut at various values of operating speeds and feeds.
\end{abstract}

Key words: Dynamics modeling, Tool geometry; Force-feed: Stab.

\section{Introduction}

Prediction of unstable operating conditions is vital imporant in machning preactice. The unstable phenomenon known as chatter eventually leads to a tool damage and loss of work surface. Machine tool operators often select the conservative process parameters from the stability lobe diagrams. Analytical prediction of stability in turning and boring is well established with flexible cutting tool models. One of the earliest models was developed by Merrit (1965). Later on, the mechanics of instability was recognized by Tlusty and Polacek (1963) and Tobias and Fishwick(1958). They obseved the cutting forces have been dynamically influenced by the modulated chip thickness. Tlusty and Polacek (1963) model employed only one direction along the chip thickness and it can be still effectively employed in straight turning without inclination angles. Later many authors have shown stability in with two dimensional models (Kaneko et al, 1984; Minis et al, 1990 and Rao and Shin 1999). Ozdagnalar and Endres presented analytical stability analysis of multidimensional cutting systems (Ozdoganlar and Endres 2000). The more general model requires inclusion of oblique cutting conditions and multidimensional dynamics for obtaining accuracy. In this regards more recently Ozlu and Budak illustrated a multidimensional turning model for oblique cutting (Ozlu and Budak 2007). This accounts relative tool motion in both feed and rotation directions and also includes the effects of nose radius on the chatter stability.

In all the above chatter analysis procedures a linear forcemodel is used to assess the stability. These do not account the * Corresponding author: E-mail: krk_ipe@yahoo.co.in static feed variations in regeneratin models. In practice force various nonlinearly with feed and depth of cut. To study the effect of nonlinear force. Zhang and $\mathrm{Ni}$ approximately included the force-feed nonlinearity in by considering modulation phase difference in the process (Zhang and Ni 1995). Landers and Ulsoy demonstarated the methods of handling force-feed nonlinearity in chatter predictions (Landers and Ulsoy 2008). Analysis is developed for turning and milling processes (Insperger et al, 2008). considered such a forcefeed terms in their model while explaining the state-dependent regenerative delay concept. A similar force-feed effect taken in boring operations is demonstarted by Pratt and Nafeh (Pratt and Nayfeh 2001). But these non-linear forcefeed models are one-dimensional and cannot be used in oblique cutting cinditions (Pratt, 2001).

In the present paper analytical multidimensional stability equations are formulated by considering nonlinear forcefeed effect in turning using three-dimensional tool geometry. Feed and radial forces are included in the model appropriately and dynamic equations are developed. The revised expression for stable depth of cut as a function chatter frequency is derived. Effect of feed on stability shown in stability lobe diagrams have been tested in time domain by solving the coupled delay differential equations. Based on the critical depth of cut at various conditions of feed and speed, experiments are conducted on a flexible work-piece to conform the effect of feed on stability. 


\section{Dynamic cutting force models}

The basic parameters in turning process are chip thickness h, the depth of cut $b$ and the cutting angles. The side cutting edge angle $(\psi)$ is measured ont the rake face of the tool. The relation between the forces and chip thickness is obtained by considering the coordinate systems: $\mathrm{x}$ (feed), y (radial) and $\mathrm{z}$ (cutting) as shown in Fig. 1. Dynamic displacement in cutting (z) direction does not affect the chip thickness.

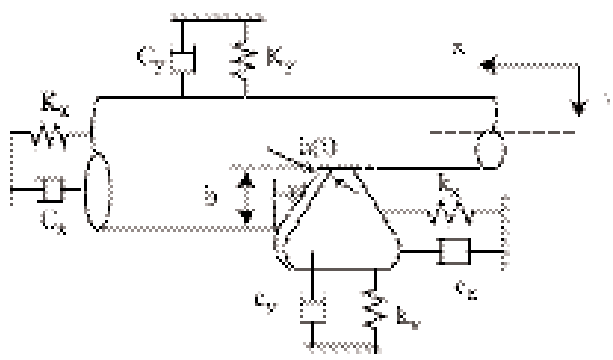

Fig. I Dynamic Model of turnigg

(b: depth of cut, h (t): chip-thickness, $\psi$ : side cutting edge angle)

The modulated chip thickness resulting from vibrations of the tool and work-piece is expressed as :

$\mathrm{h}(\mathrm{t})=\mathrm{h}_{0} \cos \psi+\left[\left(\mathrm{x}_{\mathrm{c}}(\mathrm{t})-\mathrm{x}_{\mathrm{w}}(\mathrm{t}-\tau)\right)-\left(\mathrm{x}_{\mathrm{c}}(\mathrm{t}-\tau)-\mathrm{x}_{\mathrm{w}}(\mathrm{t}-\tau)\right)\right] \cos \psi-\left[\mathrm{y}_{\mathrm{c}}(\mathrm{t})-\right.$ $\left.\left.\mathrm{y}_{\mathrm{w}}(\mathrm{t})\right)-\left(\mathrm{y}_{\mathrm{c}}(\mathrm{t}-\tau)-\mathrm{y}_{\mathrm{w}}(\mathrm{t}-\tau)\right)\right] \sin \psi$

Here $h_{0}$ is the nominal feed per revolution, $x_{c}(t), y_{c}(t), x_{w}(t)$ and $\mathrm{y}_{\mathrm{w}}(\mathrm{t})$ are the cutter and work-piece displacements in the current pass and $\mathrm{x}_{\mathrm{c}}(\mathrm{t}-\tau), \mathrm{y}_{\mathrm{c}}(\mathrm{t}-\tau), \mathrm{x}_{\mathrm{w}}(\mathrm{t}-\tau), \mathrm{y}_{\mathrm{w}}(\mathrm{t}-\tau)$ are thatin previous pass along $\mathrm{x}$ and $\mathrm{y}$ directions respectively. Also $\tau$ is the time required for one spindle revolution.

For convenience, Eq(1) can be written as

$\mathrm{h}(\mathrm{t})=\mathrm{h}_{\mathrm{s}}+\Delta \mathrm{x} \cos -\Delta \mathrm{y} \sin \psi$

where $\mathrm{h}_{\mathrm{s}}=\mathrm{h}_{0} \cos \psi$

$\Delta \mathrm{x}=\left(\mathrm{x}_{\mathrm{C}}(\mathrm{t})-\mathrm{X}_{\mathrm{w}}(\mathrm{t})\right)-\left(\mathrm{x}_{\mathrm{C}}(\mathrm{t}-\tau)\left(\mathrm{x}_{\mathrm{w}}(\mathrm{t}-\tau)\right.\right.$

$\Delta \mathrm{y}=\left(\mathrm{y}_{\mathrm{c}}(\mathrm{t})-\mathrm{y}_{\mathrm{w}}(\mathrm{t})\right)-\left(\mathrm{y}_{\mathrm{c}}(\mathrm{t}-\tau) \mathrm{y}_{\mathrm{w}}\left(\mathrm{y}_{\mathrm{w}}(\mathrm{t}-\tau)\right)\right.$

The cutting operation is three dimensional in nature due to the existence of inclination angle. Now the forces at the cutting edge are modeled with oblique cutting model. The forces acting on the cutting edge are feed force $F_{f}$ and radial force $F_{r}$ which are expressed as

$\mathrm{F}_{\mathrm{f}}=\frac{\mathrm{K}_{\mathrm{f}}}{\cos \psi} \mathrm{bh}^{a}(\mathrm{t})$

$\mathrm{F}_{\mathrm{r}}=\frac{\mathrm{K}_{\mathrm{r}}}{\cos \psi} \mathrm{bh}^{\beta}(\mathrm{t})$

Here $\mathrm{K}_{\mathrm{f}}, a, \mathrm{~K}_{\mathrm{r}}, \beta$ are the empirically determined cutting coeffients in feed and radial directions. Substituting $\mathrm{h}(\mathrm{t})$ from Eq.(2) and linerizing the forces about $h_{s}$, we can write Eqs. (6) and (7) as

$\mathrm{F}_{\mathrm{f}}=\frac{\mathrm{K}_{\mathrm{f}}}{\cos \psi} \mathrm{b}\left[\mathrm{h}_{\mathrm{s}}{ }^{a}+a \mathrm{hs}^{\alpha-1}(\Delta \mathrm{x} \cos \psi-\Delta \mathrm{y} \sin \psi)\right]$

$\mathrm{F}_{\mathrm{r}}=\frac{\mathrm{K}_{\mathrm{r}}}{\cos \psi} \mathrm{b}\left[\mathrm{h}_{\mathrm{s}}{ }^{\beta}+\beta \mathrm{h}_{\mathrm{s}} \beta-1(\Delta \mathrm{x} \cos \psi-\Delta \mathrm{y} \sin \psi)\right]$

Since static chip-thickness does not contribute to the regeneration, the first term in equations (8) and (9) can be eliminated as in earlier models.

Now resolving the forces $\mathrm{F}_{\mathrm{f}}$ and $\mathrm{F}_{\mathrm{r}}$ along $\mathrm{x}$ and $\mathrm{y}$ directions:

$\mathrm{F}_{\mathrm{x}}=\mathrm{F}_{\mathrm{f}} \cos \psi+\mathrm{F}_{\mathrm{r}} \sin \psi=\frac{\mathrm{b}}{\cos \psi}[(\mathrm{p} \Delta \mathrm{y}+\mathrm{q} \Delta \mathrm{x}) \sin \psi \cos \psi$

$\left.-\left(\mathrm{p} \Delta \mathrm{x} \cos ^{2} \psi+\mathrm{q} \Delta \mathrm{y} \sin ^{2} \psi\right)\right]$

$\mathrm{F}_{\mathrm{y}}=\mathrm{F}_{\mathrm{f}} \cos \psi+\mathrm{F}_{\mathrm{r}} \sin \psi=\frac{\mathrm{b}}{\cos \psi}[(\mathrm{p} \Delta \mathrm{y}-\mathrm{q} \Delta \mathrm{x}) \sin \psi \cos \psi$

$\left.-\left(\mathrm{p} \Delta \mathrm{y} \cos ^{2} \psi-\mathrm{q} \Delta \mathrm{y} \sin ^{2} \psi\right)\right]$

where $\mathrm{p}=\mathrm{K}_{\mathrm{f}} \alpha \mathrm{h}_{\mathrm{s}}{ }^{\alpha-1}$ and $\mathrm{q}=\mathrm{K}_{\mathrm{r}} \beta \mathrm{h}_{\mathrm{s}}{ }^{\beta-1}$

The equations can be written in matrix form as

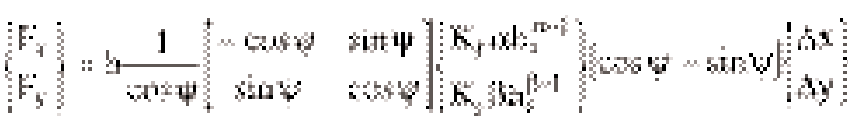

These equations can be rewritten as

$\{\mathrm{F}\}=\mathrm{b}[\mathrm{A}]\{\Delta \mathrm{d}\}$

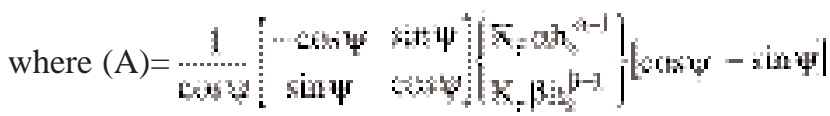

\section{Stability analysis}

Taking Laplace transforms on both sides of Eq. (13)

$\mathrm{F}(\mathrm{s})=\mathrm{b}\{\mathrm{A}\}\left(1-\mathrm{e}^{-\mathrm{s} \tau}\right) \mathrm{D}(\mathrm{s})$

By considering the transfer function matrix $\{\mathrm{G}(\mathrm{s})\}$ of the system, it is possible to write $\mathrm{D}(\mathrm{s})$ as $\{\mathrm{G}(\mathrm{s})\} \mathrm{F}(\mathrm{s})$. Hence $\mathrm{Eq}$. (15) becomes:

$\mathrm{F}(\mathrm{s})=\mathrm{b}\{\mathrm{A}\}\left(1-\mathrm{e}^{-\mathrm{s \tau}}\right)[\mathrm{G}(\mathrm{s})] \mathrm{f}(\mathrm{s})$

Substituting $s=j \omega$, Eq. (16) in frequency domain turns to:

$F(j \omega s)=b(A]\left(1-e^{-j \omega \tau}\right)[G(j \omega)] F(j \omega)$

This equation has non-trivial solution if andonly if its determinant is zero, yielding:

$\left.\operatorname{det}\{\mathrm{I}\}-\lambda\left[\mathrm{G}_{0}\right]\right\}=0$

where $\left[G_{0}\right]=[A]\left[G(j \omega)\right.$ and $\lambda=b\left(1 e^{-j \omega \tau}\right)$

This eigenvalue problem given by Eq. (18) can be directly solved to obtain the complex eigenvalue $\lambda$ By considering 
the transfer matrix as $[G(j \omega)]$

$=\left[\begin{array}{cc}G_{x x}(j \omega) & 0 \\ 0 & G_{y y}(j \omega)\end{array}\right]$, the Eigen value can be obtained as $\lambda=\frac{\cos \psi}{\left(p \cos ^{2} \psi-q \sin \psi \cos \psi\right) \mathrm{G}_{\mathrm{xx}}+\left(\mathrm{q} \sin ^{2} \psi+q \sin \psi \cos \psi\right) \mathrm{G}_{\mathrm{yy}}}$

writing $\lambda$ from Eq. (19) as

$\lambda=\lambda_{\mathrm{R}}+\lambda_{\mathrm{I}}=\mathrm{b}(1-\cos \omega \tau)+\mathrm{j} b \sin \omega \tau$

The phase shift $\mathrm{k}=\frac{\lambda_{\mathrm{I}}}{\lambda_{\mathrm{R}}}$ can be defined from Eq. 21according to

$\frac{\lambda_{\mathrm{I}}}{\lambda_{\mathrm{R}}}=\frac{\sin \omega \tau}{1-\cos \omega \tau}=1 / \tan \frac{\omega \tau}{2}=\tan \left(\frac{\pi}{2}+\mathrm{n} \pi-\frac{\omega \tau}{2}\right)$

This gives the critical values of $\tau$ as

$\tau^{*}=\frac{2}{\omega}\left\{\left(\mathrm{n}+\frac{1}{2}\right) \tau-\mathrm{a} \tan \left[\frac{\lambda_{1}}{\lambda_{\mathrm{R}}}\right]\right\}$ where $\mathrm{n}=0,1,2 \ldots$

The corresponding critical values of $\mathrm{b}$ is given by

$\mathrm{b}^{*}=\frac{\lambda_{\mathrm{R}}}{1-\cos }$

By writing spindle speed in rpm as $\mathrm{N}=60 / \tau$, stability lobe diagram can be plotted between the values of $b^{*}$ and $\mathrm{N}$ for different values of $n$. The second order delay differntial equation in time domain are solved at a specific testing depth of cut and feed conditions using revised fourth order RungeKutta method.

\section{Results and Discussion}

Based on the proposed analytical model, stability analysis is conducted. The cutting material parameters used in the simulation (Ozlu and Budak 2007)are given in Table I.

\section{Table I. Cutting and material data}

\begin{tabular}{|c|c|}
\hline Cutting tool & work-piece \\
\hline Natural frequency & Modulus of elasticity E \\
\hline$\omega_{\mathrm{nxc}}=\omega_{\mathrm{nyc}}=1100 \mathrm{~Hz}$ & $=2.1 \times 10^{7} \mathrm{~N} / \mathrm{m}^{2}$ \\
\hline Stiffness $\mathrm{k}_{\mathrm{x}}=\mathrm{k}_{\mathrm{y}}=1.2 \times 10^{7} \mathrm{~N} / \mathrm{m}^{2}$ & Density $\rho=7800 \mathrm{Kg} / \mathrm{m}^{3}$ \\
\hline Damping ratio $\zeta_{x}=\zeta_{y}=0.015$ & Diameter d=39 mm \\
\hline Cutting coeffcients $\mathrm{K}_{\mathrm{f}}=800 \mathrm{MPa}$ & Length L=75 mm \\
\hline $\mathrm{K}_{\mathrm{r}}=128 \mathrm{MPa}$ & \\
\hline Side cutting edge angle $\psi=10^{\circ}$ & $\begin{array}{l}\text { Average damping ratio } \\
\zeta_{\mathrm{xw}}=\zeta_{\mathrm{yw}}=0.025\end{array}$ \\
\hline Normal rake angle $=5^{\circ}$ & \\
\hline Inclination angle $5^{\circ}$ & \\
\hline Nose radius $=0.4 \mathrm{~mm}$ & \\
\hline Working feed $=0.01-0.6 \mathrm{~mm}$ & \\
\hline
\end{tabular}

The axial (x) and bending (y) stiffness and corresponding natural frequencies $\left(\omega_{\text {nxc }}, \omega_{\text {nyc }}\right)$ of the work are computed by considering cantilever boundary conditions. The tool work transfer function matrices are evaluted according to:

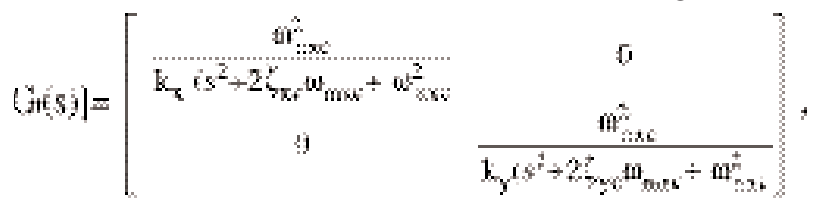

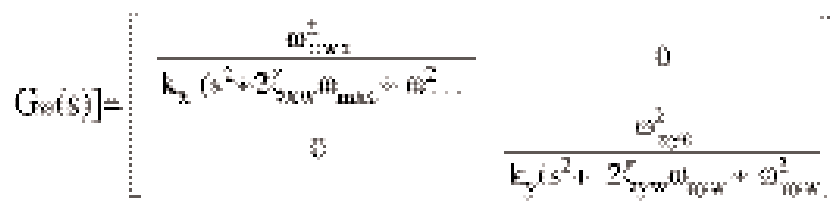

Using the proposed stability model the feed effect on the cutting stabiltity is shown in Fig. 2 as a feed depth stability lobe diagram at speed of $\mathrm{N}_{\mathrm{s}}=9042 \mathrm{rpm}$.
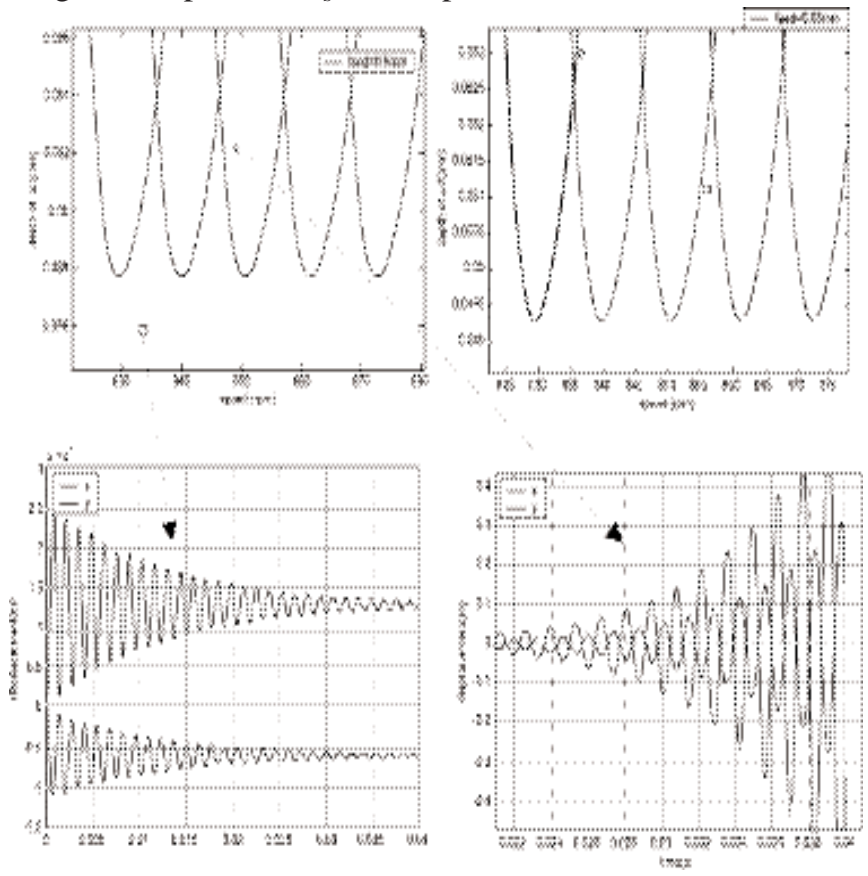

Fig. 2. Stability lobe diagrams from the proposed model

Critical depth of cut increases with feed at all the spindle speed values. At low values of a a comparatively more change in lobe diagram is noticed. Also it can be seen that the width of lobe has increased due this nonlinear force effect. The effect is verfied from the time domain analysis. Fig. 3 shows the time domain response of tool displacement and cutting forces under two different feed conditions at common depth of cut.

Prediction of chatter with time domain analyisis requires testing over all the operating regions. Thus it becomes 


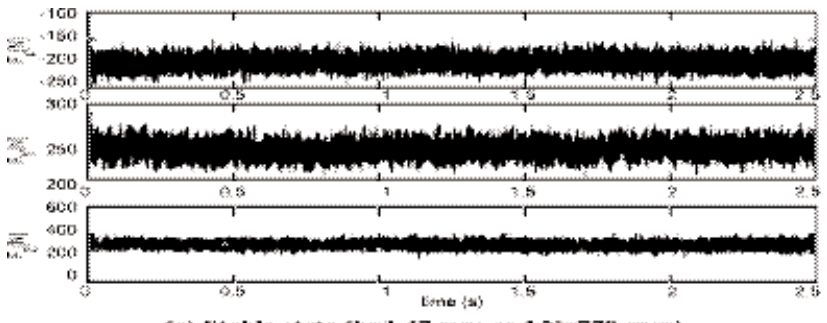

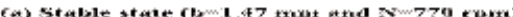

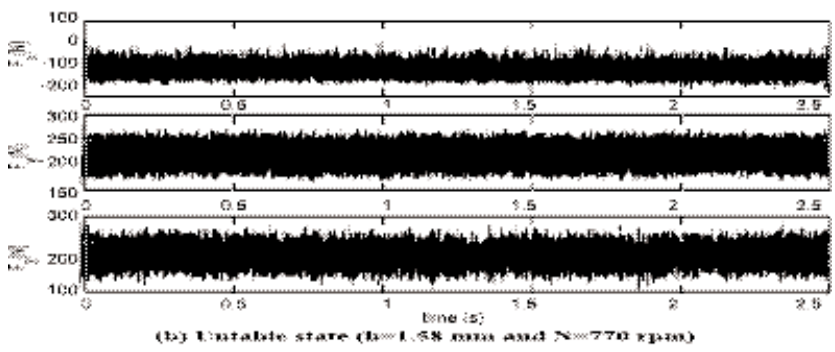

Fig. 3. Time domain response of tool displacement ands cutting forces

lengthy procedure in regular cases. On the other hand, the method of frequency sweeping to obtain the stability lobes leads to modeling errors in the process. Hence in order to predict the critical depths of cuts at various operating feeds and speeds, a neural network approach is proposed.

\section{Conclusion}

Effects of nonlinear force-feed conditions in chatter stability of turning operation have been presented in this paper. It is observed that in all the cases the critical depth of cut increase with feed. When the nonlinear feed exponent is less than one as in regular metals, the effect is more pronounced. Practically an increase in feed minimizes the cycle time, but machining forces also increase with feed. So it cannot be used to supperss chatter. Due to the inclusion of feed in chatter relations. it is possible to calibrate the force models at any feed. In practical contions, the cutting cofficients also change with feed. The influence is ignored in the analytical model.

\section{References}

Merrit H. E. (1965) Theory of self-excited machine tool chatter, ASME Journal of Engineering for Industry, 87(4): 4447-454.

Tlusty J. and Polacek M. (1963) The stability of machine tools against self excited vibrations in machining, Int. Res. Prod. Eng. ASME, 22m,pp.465-474.
Tobias S. A. and Fishwick W. (1958) The chatter of lathe tools under orthogonal cutting vibrations in machining," Int. Res. Prod. Eng. ASME, 22: 465-474.

Tobias S. A. and Fishwick W. (1958) The chatter of lathe tools under orthogonal cutting conditions, Trans. ASME 80(2): 1079-1088.

Kaneko T., Sato H., Tani T. and Ohori M. (1984) SelfExcited Chatter and its marks in Turning, Journal of Engineering for Industry-Trans ASME, 222(2), pp.106228.

Minis I. E., Magrab E. B. and Pandelidis I. O. (1990) Improved methods for the prediction of chatter in turning part-32: a generalized linear theory, ASME Journal of Engineering for Industry, 112: 12-20.

Rao C. B. and Shin Y. C. (1999) A comprehensive dynamic cutting force model for chatter prediction in turning, Int. J. Machine Tools and Manufacture, 39: 16311654.

Ozdoganlar O. B. and Endres W. J. (2000) An Analytical Representation of Chip Area for Corner-Radiused Tools under Both Depth-of-Cut and Feed Variations. ASME J. Mfg. Sci. and Engg., 122: 660-665.

Ozlu E. and Budak E. (2007) Analytical Modeling of Chatter Stability in Turning and Boring Operations: A MultiDimensional Approach, CIRP Annals- Manufacturing Technology, 56(1): 401-404.

Zhang H. Y. and Ni J. (1995) Phase Difference and Its and Its Sensitivity Analysis for a Nonlinear DifferenceDifferentail Machining Chatter Model,: Trans of NAMRI, 23: 131-136.

Landers R. G. and Ulsoy A. G (2008) Nonlinear feed effect in Machining chatter analysis, ASME J. Manufacturing Science and Engineering, 130(1): 17-26.

Insperger T., Barton D. A.W. and Stepan G., 2008, Criticality of Hopf bifurcation in state-dependent delay model of turning process, Int. J. Nonlinear Mechanics, 43(2): 140-149.

Pratt J. R. and Nayfeh A. H. (2001) Chatter control and stability analysis of cantilever boring bar under regenerative chatter, Philosophical Transactions of Royal Society, 359(1781): 759-792.

Received : April 09, 2008;

Accepted : Jugust 09, 2009 